\title{
Dynamics properties of a Go-kart chassis structure and its prediction improvement using model updating approach
}

\author{
N.A.Z. Abdullah 1,", M.S.M. Sani1 ${ }^{1,}$, N.A. Husain ${ }^{2}$, M.M. Rahman ${ }^{3}$ and I. Zaman ${ }^{4}$ \\ ${ }^{1}$ Advanced Structural Integrity of Vibration Research (ASIVR), Faculty of Mechanical \\ Engineering, University Malaysia Pahang, 26600 Pekan, Pahang, Malaysia \\ ${ }^{2}$ Automotive Department, Faculty of Mechanical Engineering, \\ Universiti Teknologi Malaysia (UTM), 81310 Skudai, Johor Bahru, Johor, Malaysia \\ ${ }^{3}$ Faculty of Mechanical Engineering, University Malaysia Pahang, \\ 26600 Pekan, Pahang, Malaysia \\ ${ }^{4}$ Department of Engineering Mechanics, Faculty of Mechanical and Manufacturing \\ Engineering, Universiti Tun Hussein Onn Malaysia, \\ 86400 Parit Raja, Batu Pahat, Johor, Malaysia \\ *Email: znooramzura@hotmail.com,mshahrir@ump.edu.my
}

\begin{abstract}
Model updating is concerned about the correction of finite element models by processing the record of dynamic response from test structures in order to have an accurate model for any simulated analysis. Finite element model updating had emerged years ago as an important subject in structural dynamics. It has been used frequently and has been successfully applied to many fields especially in detecting the dynamic stiffness of a structure. The purpose of this study is to perform model updating of a go-kart chassis structure in order to reduce the percentage of error between the experimental modal analysis (EMA) and finite element analysis (FEA). Modal properties (natural frequency, mode shapes, and damping ratio) of the go-kart chassis structure were determined using both EMA and FEA. Correlation of the modal parameters gathered in FEA and EMA was carried out before optimizing the data from finite element. By adjusting the selective parameters, incongruities between those two analyses are generally reduced. The sensitivity of selected parameters is also obtained. The significant reduction in percentage of error before and after model updating procedure was carried out in this study clearly shows that model updating technique is a reliable method in reducing the discrepancies between EMA and FEA. Therefore, in cases of high discrepancies between analytical and actual test data, model updating can be considered as an option in order to obtain better correlation between those two sets of data.
\end{abstract}

Keywords: Model updating; modal analysis; go-kart frame structure; impact hammer test.

\section{INTRODUCTION}

A go-kart structure refers to the small four-wheeled vehicle that is used in sports and recreation. By the definition stated by International Karting Commission - Federation International Automobile (CIK-FIA), go-kart is a land vehicle with or without a bodywork, with four non-aligned wheels in contact with the ground, two of which control the steering while the other two transmit the power. Apart from the engine and attached wheels, the chassis of a go-kart usually consists of a body frame made up of steel pipes that are welded together. There are quite a number of studies that have been carried out 
concerning go-karts. This includes the study about the design of its frame or chassis that sometimes were concerned about the selection of materials for the structure, simple structural analysis, safety, and also the stability of the structure [1-4]. Currently, the trend in chassis design is focusing on producing lower cost and lighter vehicle structure but with good safety efficiency. However, a lighter chassis structure will cause the structural resonance within the typical rigid body vibration to easily occur due to induced dynamic forces by road irregularities, engine, and other loads. This situation can result in riding discomfort and problems in ride safety and stability [5-8]. Computer based analysis techniques such as the finite element method proves to be a reliable tool in engineering design and product development [9]. Furthermore, finite element model updating is already considered as an important subject to design, in terms of construction and maintenance of mechanical systems and civil engineering structures [10] since it is viewed as a convenient tool for analysing and predicting the dynamic performance of various structures [11-15]. For example, Mottershead and Friswell with their partners have done quite a study of model updating using FEA and have proven the reliability of finite element model in providing desired outcomes [4, 16-19]. The EMA is the classic method of obtaining the modal parameter of a certain structure [20]. The frequently used method of carrying out the experiment is by using impact hammer as an actuator, an accelerometer as the sensor, and a Fast Fourier Transform (FFT) analyser to obtain the system Frequency Response Function (FRFs) between the excitation and the structural response [21].

On the other hand, model updating is viewed as an important process of modifying certain parameters of a finite element to reduce the discrepancies between the computational model and the actual structure of the test subject. There are a lot of sources of modelling error that can affect the dynamic properties of the modelled structure and thus, these bring discrepancies to the actual model [22-24]. Generally, model updating is performed whether by using response based method or modal based method. In response based model updating, the finite element model directly makes use of the FRF for updating. Meanwhile, in modal based model updating, the modal data are applied in the structural parameter updating procedure, usually by doing optimization. There are quite a number of explorations done with regards to model updating technique. For example, several studies done previously have highlighted various methods of conducting model updating [16, 22, 25-30]. Viewing updating parameter is an important subject and is the key of successful model updating. Quite a number of researchers have emphasized on parameterization issue such as Bohle and Fritzen [31]. Similarly, Chen and his partner also discussed the parameter topic in their study [32]. Model updating technique has also been performed on miscellaneous types of structures [33]. For instance, Abu Husain has demonstrated model updating technique on welded flat plate and hat-shape structure [34], which from the initial correlation exhibits percentage of errors of below 5\%. However, after carrying model updating procedure, the level of discrepancies is reduced to below $3 \%$. Aside from this, there are many investigations of model updating procedures on other structures such as complex aerospace structures, bridges, and others [16, 18, 22, 34, 35]. Model updating is already a frequent field of study. Even so, most of the studies are focused on localization model updating which concerns joints elements. However, this study concerns with globalization model updating procedure that takes the whole structure into consideration. In this paper, the application of modal based model updating is performed on a go-kart chassis structure in order to minimize the error percentage between experimental data and finite element data. Thus, the updated model of the gokart chassis structure can be considered to represent the actual counterpart in better 
manner. The findings of this study can be a guide for other scholars to perform the study of model updating on other structures in other works.

\section{METHODS AND MATERIALS}

\section{Finite Element Analysis}

In FEA, frequency analysis is performed on the finite element model of the go-kart structure to obtain the dynamic properties of the structure, which are the natural frequencies, damping ratios, and the mode shapes of the structure. A wireframe model of the go-kart structure is developed according to the dimension of the actual test go-kart structure. The thin-walled pipe profile; which is the outer diameter, and the thickness of the wall are set to be the same as the real structure, and are then assigned to the wireframe structure. Figure 1 shows the go-kart structure with the pipe profile rendered to the wireframe structure.

The FEA on the model is carried out using ABAQUS software. Meshing is created on the wireframe structure. Since the model is made up of wireframe structure, namely tetrahedral, wedge elements cannot be created. Instead, one-dimensional beam element is created. A total of 965 elements, which used simple beam elements with 963 nodes, are created on the whole go-kart structure at $0.005 \mathrm{~m}$ approximate global meshing sizes which based on mesh independence tests, show converge desired output. The free-free boundary condition, which has neither constraints nor loads, is assigned to the structure in order to simulate its natural frequencies and mode shapes as it is much more easier to approximate experimentally and analytically $[32,36]$. The material adopted on the structure is highcarbon steel, whereas the adopted value of density is $7,860 \mathrm{~kg} / \mathrm{m}^{3}$ and the Young's modulus is $235 \mathrm{GPa}$. The analysis is performed in linear perturbation procedure type and the history output request is frequency. The model is validated by comparing the finite element model mass to the actual part which is around $8 \mathrm{~kg}$.
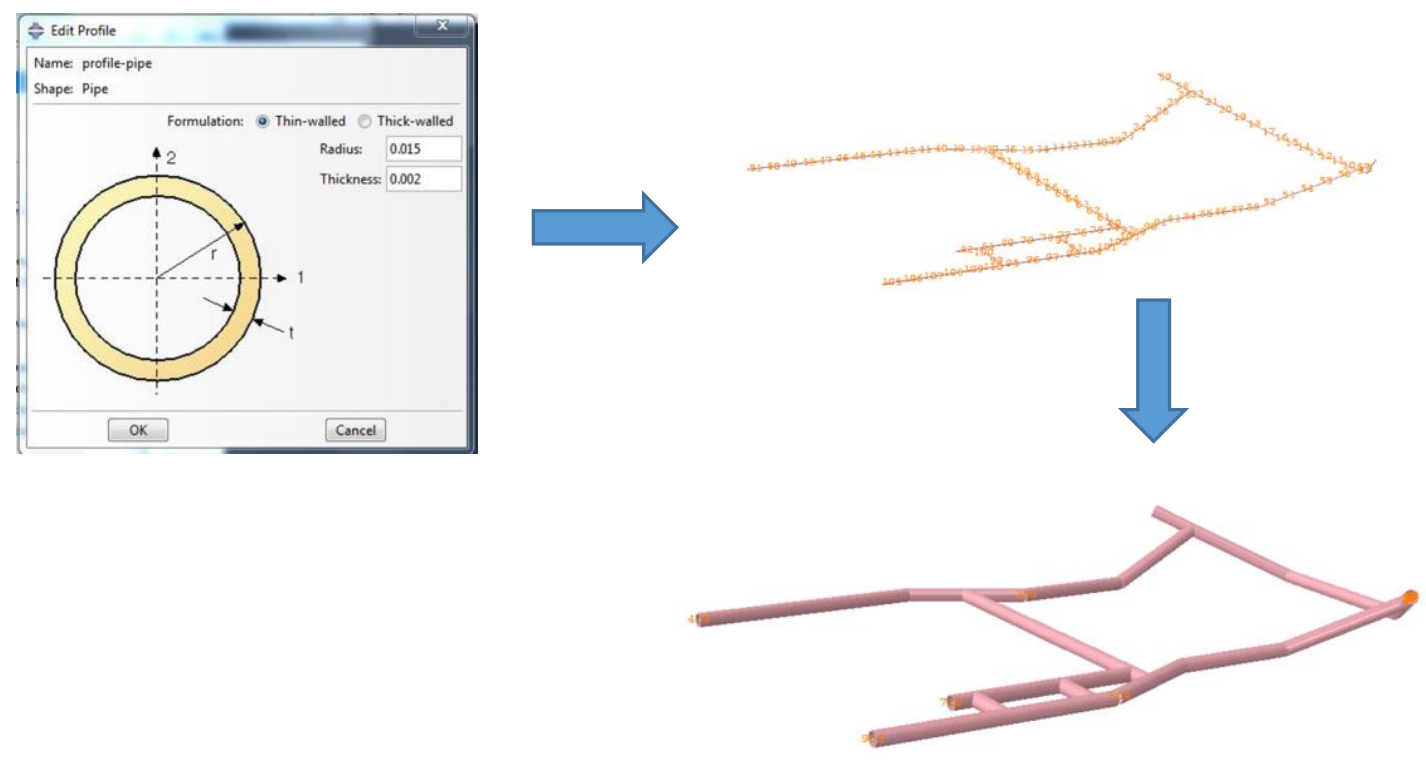

Figure 1: Finite element model of go-kart chassis structure.

The minimum frequency of interest is set as $1 \mathrm{~Hz}$ in order to avoid the calculation of rigid body mode which has the frequency at $0 \mathrm{~Hz}$, while there is no maximum frequency of interest limited in the setting of the analysis. However, five numbers of 
eigenvalues are requested for the analysis since this study intends to focus only on the first five vibrational modes of the structure. Figure 2 shows the computed mode shape and the natural frequencies calculated for the go-kart chassis structure. The natural frequency for the first mode is $40.24 \mathrm{~Hz}$, the second mode is $60.66 \mathrm{~Hz}$, the third mode is $72.97 \mathrm{~Hz}$, the fourth mode is $73.49 \mathrm{~Hz}$, and the fifth mode is $110.36 \mathrm{~Hz}$.

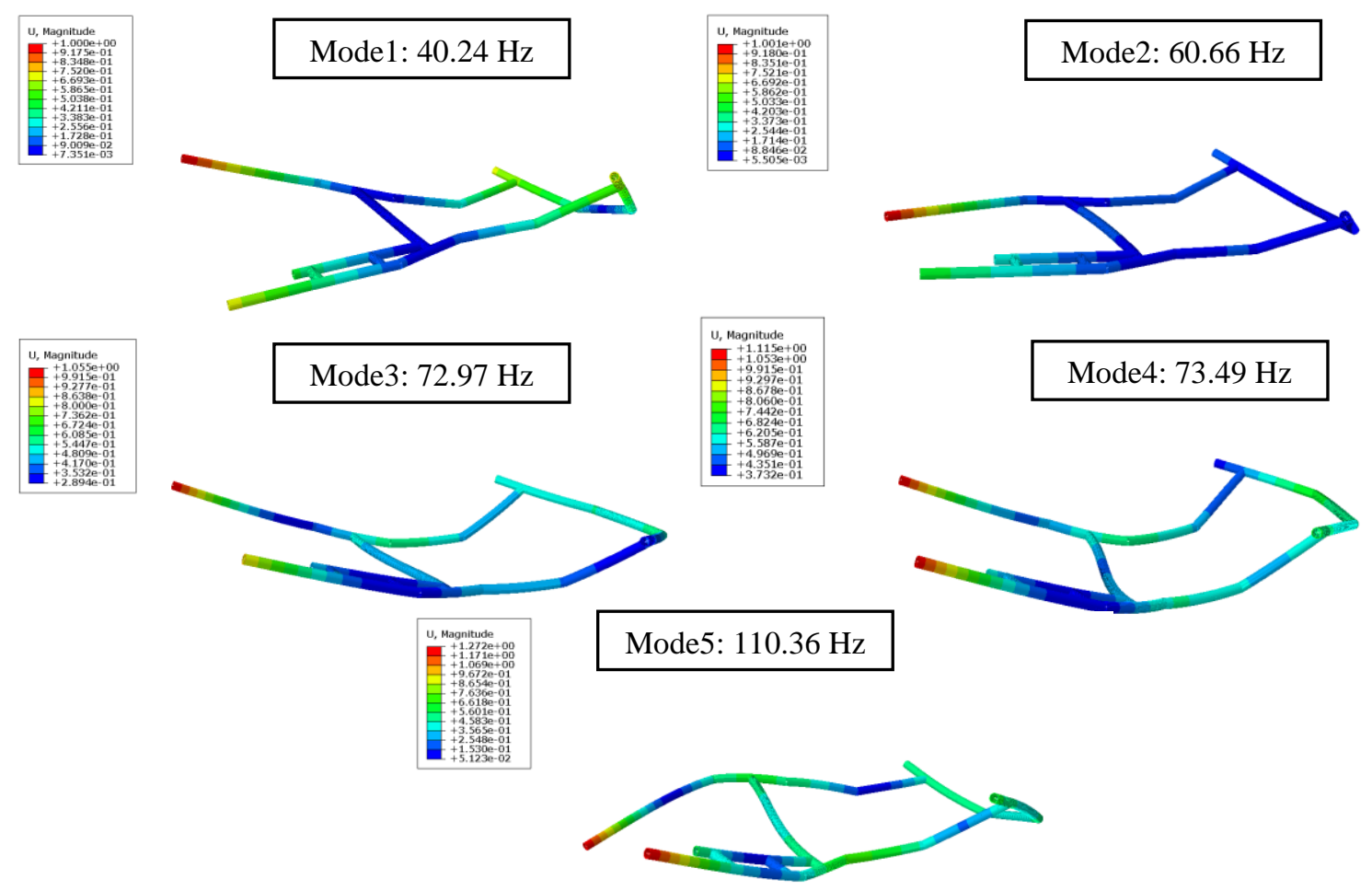

Figure 2: Predicted natural frequencies and mode shapes of the go-kart.

\section{Experimental Modal Analysis}

Modal parameters including the natural frequencies, mode shapes, and the damping ratios can be obtained using a curve-fitting process or modal parameter extraction method. In this case, those modal parameters are extracted using curve-fitting process. Curve fitting process which is also called modal parameter estimation was implemented using postprocessing software called ME'ScopeVES. Frequency domain data was used for performing the curve fitting. The equipment used in the EMA includes the impact hammer, the data acquisition device, and also the triaxle accelerometer as shown in Figure 3. The test subject is put in free-free boundary condition as shown in Figure 4 where the go-kart chassis frame is suspended using elastic rope. Excitation method used in this experiment is the impact hammer test. The experiment is carried out using roving accelerometer method where the triaxle accelerometer as the sensor is roved from one point to another point on the test structure, while the hammer is used to give excitation at a single fix point.

Figure 5 shows the FRF generated at 61 points during the impact hammer test. On the other hand, Figure 6 shows the experimental mode shape and the natural frequencies at the selected five modes. Based on the experiment, the natural frequency for the first mode is $38.5 \mathrm{~Hz}$, the second mode is $57.0 \mathrm{~Hz}$, the third mode is $68.2 \mathrm{~Hz}$, the fourth mode is $74.2 \mathrm{~Hz}$, and the fifth mode is $101.0 \mathrm{~Hz}$. 


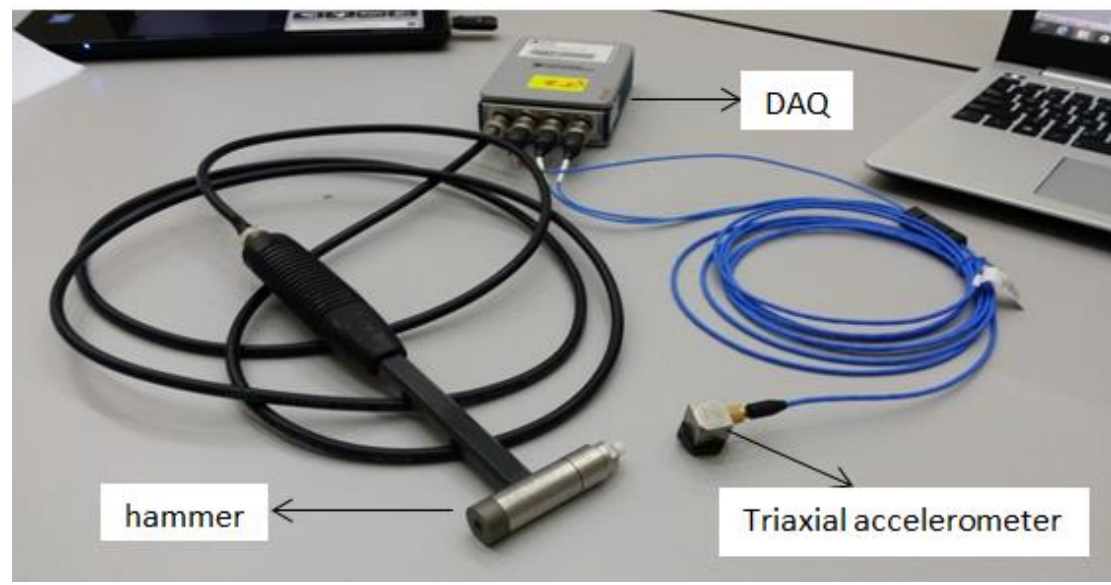

Figure 3. Equipment for experimental modal analysis (EMA).

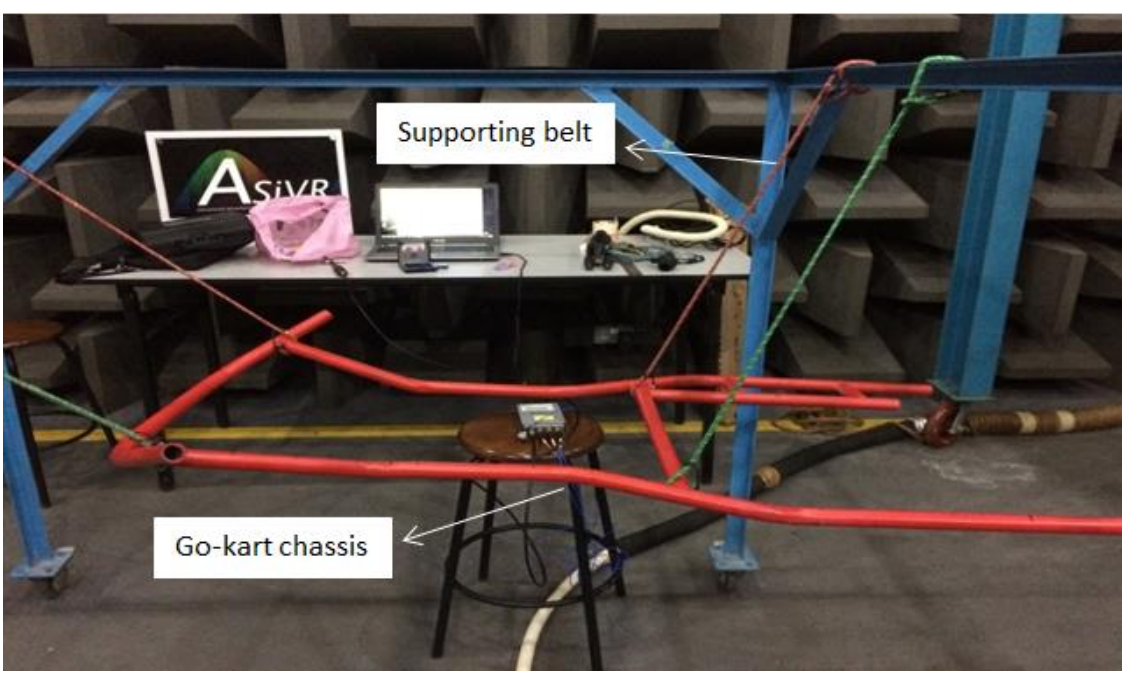

Figure 4. Experimental set up for the EMA.

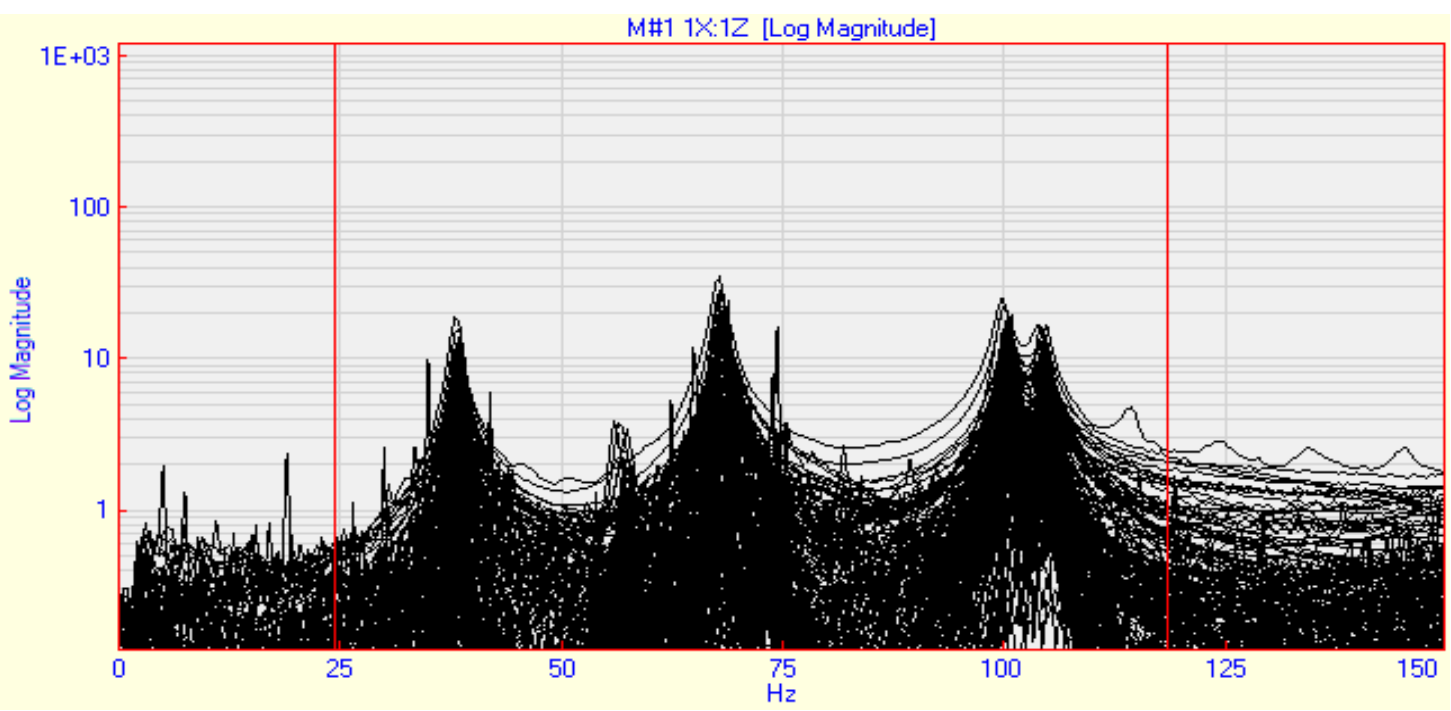

Figure 5. Superimposed FRFs by impact hammer test. 

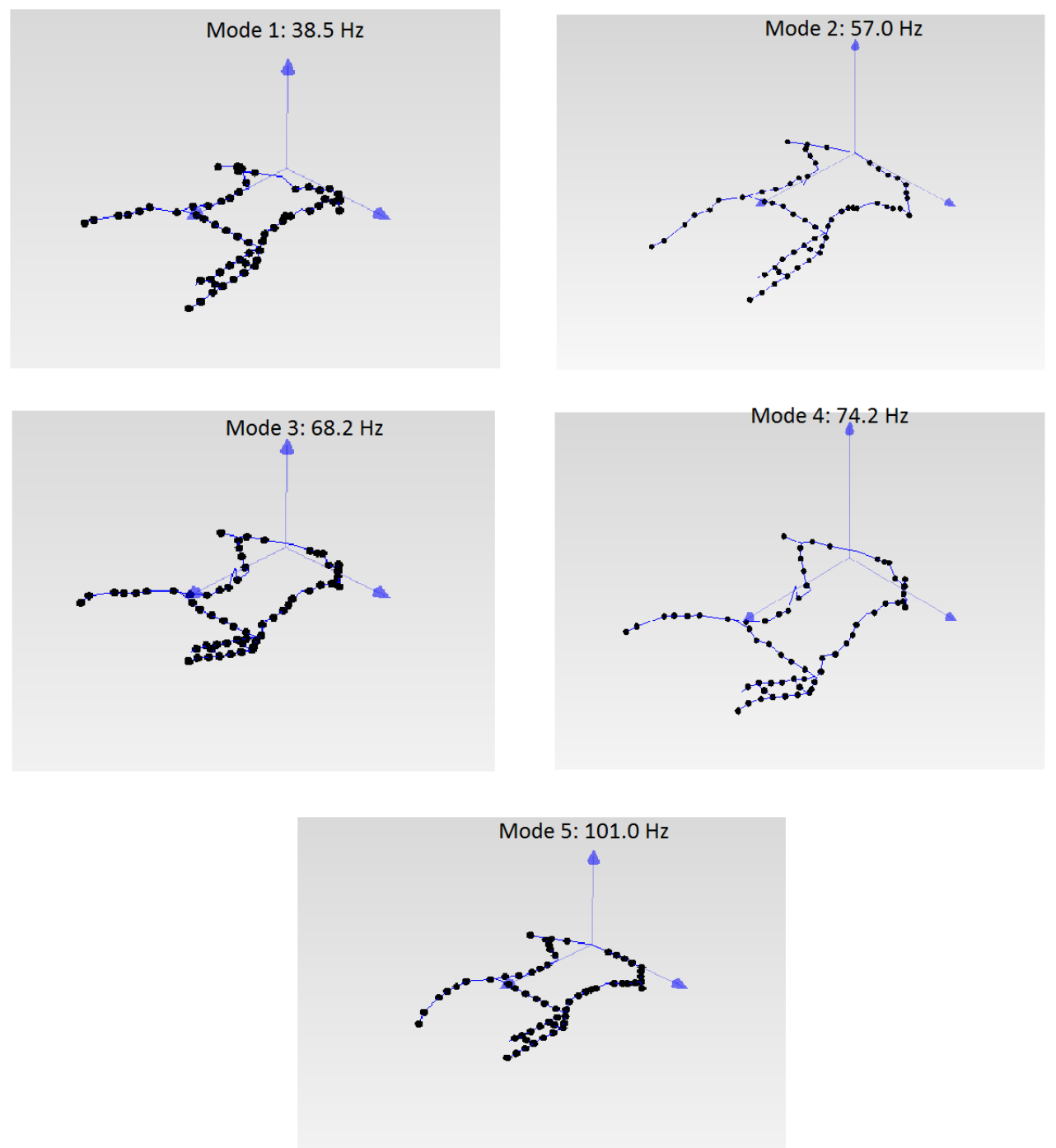

Figure 6. Measured natural frequencies and mode shapes of the go-kart structure.

\section{RESULTS AND DISCUSSION}

Correlation is a process of comparing the data from FEA to the EMA and assessing how far that they are in agreement with each other. It is certain that discrepancies are unavoidable due to error possibilities in experimental data or finite element model structure [33, 37]. The results of FEA and EMA are correlated to determine the inconsistencies between both analyses. After correlating, model updating is performed so that the percentage of error between them can be reduced. Table 1 provides the correlation of natural frequencies of the go-kart chassis structure extracted from both FEA and EMA. From Table 1, it clearly shows that the frequencies value in FEA is different from the data in EMA and thus, proving there is significant value of error which rose due to less accurate input data. Mottershead and others provided a detailed discussion about sources of error that are possible in numerical analysis which consist of idealization errors resulting from assumption, discretization errors introduced by numerical methods, and erroneous assumption for model parameters [16]. 
Table 1. Correlation between natural frequencies in EMA and FEA.

\begin{tabular}{cccc}
\hline Mode & $\begin{array}{c}\text { FEA } \\
\text { Frequency }(\mathrm{Hz})\end{array}$ & $\begin{array}{c}\text { EMA } \\
\text { Frequency }(\mathrm{Hz})\end{array}$ & Error (\%) \\
\hline 1 & 40.24 & 38.5 & 4.52 \\
2 & 60.66 & 57.0 & 6.42 \\
3 & 72.97 & 68.2 & 6.99 \\
4 & 73.49 & 74.2 & 0.96 \\
5 & 110.36 & 101.0 & 9.27 \\
\hline
\end{tabular}

\section{MODEL UPDATING}

In order to reduce the conflicts in FEA, model updating is applied to the finite element data by using the first-order optimization method. The optimization algorithm in MSC. NASTRAN (SOL200) is used for this study. The objective function for the prediction error is defined as:

$$
g(x)=\sum_{i=1}^{n} W\left(\frac{w_{i}^{e}}{w_{i}^{a}}-1\right)^{2}
$$

where $w_{i}^{e}$ and $w_{i}^{a}$ are the experimental and computational natural frequencies respectively, with $W$ as the real positive weighing factor. The prediction of the modal data is bestowed for detraction in the updating operation. The operation prolongs until convergence is achieved, where the contrariness between values of $g(x)$ from the following iteration is adequately small.

In choosing the updating parameter, eigenvalues sensitivities are estimated antecedent. Therefore, only significant parameters can be selected. After performing the sensitivity analysis using SOL200, two parameters are picked for this study, which are the Young's modulus of the go-kart chassis structure and the inner diameter of the tube structure. The original value of Young's modulus of the structure and inner thickness of the tube structure is $235 \mathrm{GPa}$ and $1.3 \mathrm{~mm}$ respectively. The Young's modulus is allotted to fluctuate from 190 to $250 \mathrm{GPa}$. At the same time, the lower and upper bound value for the inner diameter of the tube structure is allocated to be 1.2 and $1.4 \mathrm{~mm}$, correspondingly. The deviations of the updating parameters for the structure from the initial values are shown in Table 2.

Table 2. Changes of updating parameters from the initial values.

\begin{tabular}{cccc}
\hline Parameter & I & II & $\begin{array}{c}\text { Changes } \\
(\%)=|(I I-I) / I|\end{array}$ \\
\cline { 2 - 3 } & Initial value & Updated value & 0.06 \\
\hline $\begin{array}{c}\text { Young's modulus } \\
(\mathrm{GPa})\end{array}$ & 235 & 222 & 0.06 \\
$\begin{array}{c}\text { Inner diameter of } \\
\text { tube structure }(\mathrm{mm})\end{array}$ & 1.30 & 1.22 & \\
\hline
\end{tabular}

Comparison of natural frequencies values of initial FE results and the model updating results is displayed in Table 3. As the table shows, there is a significant difference between the value of natural frequency value before and after the model 
updating is performed. Percentage of error shows lessening practically. Most of the values of natural frequency after updating clearly imitate the data from the experiment. Therefore, the model updating procedure is considered as successful to minimize the discrepancies between those two sets of data.

Table 3. Comparison of natural frequencies between the initial results and updated results.

\begin{tabular}{cccccc}
\hline Mode & $\begin{array}{c}\text { EMA } \\
\text { Frequency } \\
(\mathrm{Hz})\end{array}$ & \multicolumn{2}{c}{ Initial FE results } & \multicolumn{3}{c}{$\begin{array}{c}\text { Model updating FE } \\
\text { results }\end{array}$} \\
\cline { 3 - 6 } & & $\begin{array}{c}\text { Frequency } \\
(\mathrm{Hz})\end{array}$ & Error $(\%)$ & $\begin{array}{c}\text { Frequency } \\
(\mathrm{Hz})\end{array}$ & Error $(\%)$ \\
\hline 1 & 38.50 & 40.24 & 4.52 & 38.18 & 0.83 \\
2 & 57.00 & 60.66 & 6.42 & 57.54 & 0.95 \\
3 & 68.20 & 72.97 & 6.99 & 69.22 & 1.50 \\
4 & 74.20 & 73.49 & 0.96 & 69.70 & 6.06 \\
5 & 101.00 & 110.36 & 9.27 & 104.71 & 3.67 \\
\hline
\end{tabular}

\section{CONCLUSIONS}

This study sets out to perform modal based model updating on a go-kart chassis to minimize the discrepancies between the EMA and FEA. The correlation results after performing model updating procedure show that optimization of the selected parameter is able to revise the modal data of the FE model. Simultaneously, the discrepancies between the experiment data and finite element data are successfully reduced. The discrepancies for the modal properties of interest, which is the natural frequencies, during EMA and FEA is reduced from below $10 \%$ error to below $6.1 \%$ error after performing model updating. The evidence from this study testifies that model updating technique or also called model calibration is proven to be a good method in reducing divergences. Also, the estimation for the initial input parameter such as Young's modulus and diameters of the tube can be improved. Concurrently, SOL200 is proven to be an effective algorithm for finding the sensitivity of parameters. It is recommended that further research on this structure can be conducted in future to include the joint properties as one of the updating parameters along with the existing updating parameters. More information on model updating technique would help us to establish a greater degree of accuracy on this matter. If the investigation is to be moved forward, a better understanding of model updating technique and parameterization needs to be developed.

\section{ACKNOWLEDGEMENTS}

The authors would like to express their gratitude to the Ministry of Higher Education (MOHE) for providing the FRGS fund for this study under RDU 130149.

\section{REFERENCES}

[1] Joeri VM, Jean-Marc T, Philippe L, Peter VB. Project oriented education: Build your own electric go-kart. Power Electronics and Applications, 2005 European Conference on: IEEE; 2005. p. 9 pp.-P. . 
[2] Cardoso C, Ferreira J, Alves V, Araujo RE. The design and implementation of an electric go-kart for education in motor control. International Symposium on Power Electronics, Electrical Drives, Automation and Motion, 2006 SPEEDAM 2006 IEEE; 2006. p. 1489-94.

[3] Shukri M, Rahman M, Ramasamy D, Kadirgama K. Artificial neural network optimization modeling on engine performance of diesel engine using biodiesel fuel. International Journal of Automotive and Mechanical Engineering. 2015;11:2332.

[4] Kamal M, Rahman MM, Sani MSM. Application Of Multibody Simulation For Fatigue Life Estimation. International Journal of Automotive and Mechanical Engineering. 2013;7:912-23.

[5] Sani MSM, Rahman MM, Noor MM, Ming GL. Dynamic Correlation Technique and Model Updating on Go Kart Chassis Structure. 2008.

[6] Maharun M, Baharom MB, Mohd MS. Ride comfort simulation of a vehicle equipped with semi-active steering system. International Journal of Automotive and Mechanical Engineering. 2015;11:2495-503.

[7] Zulkarnain N, Zamzuri H, Mazlan SA. Ride and Handling Analysis for an Active Anti-Roll Bar: Case Study on Composite Nonlinear Control Strategy. International Journal of Automotive and Mechanical Engineering. 2014;10:2122242.

[8] Jawi ZM, Isa MHM, Mohamed N, Awang A, Osman MR. A systemic analysis of the usage of safety items among Malaysian private vehicle users. Journal of Mechanical Engineering and Sciences. 2016;10:2262-74.

[9] Kamal M, Rahman MM. Finite element-based fatigue behaviour of springs in automobile suspension. International Journal of Automotive and Mechanical Engineering. 2014;10:1910-9.

[10] Friswell M, Mottershead JE. Finite element model updating in structural dynamics: Springer Science \& Business Media; 2013.

[11] Yuan Q. Dual approaches to finite element model updating. Journal of Computational and Applied Mathematics. 2012;236:1851-61.

[12] Rahman MM, Kadirgama K, Noor MM, Rejab MRM, Kesulai SA. Fatigue life prediction of lower suspension arm using strain-life approach. European Journal of Scientific Research. 2009;30:437-50.

[13] Rahman MM, Ariffin AK, Rejab MRM, Kadirgama K, Noor MM. Multiaxial fatigue behavior of cylinder head for a free piston linear engine. Journal of Applied Sciences. 2009;9:2725-34.

[14] Zamzamzadeh M, Saifizul AA, Ramli R, Soong MF. Dynamic simulation of brake pedal force effect on heavy vehicle braking distance under wet road conditions. International Journal of Automotive and Mechanical Engineering. 2016;13:355563.

[15] Elkady M, Elmarakbi A, MacIntyre J. Integration of vehicle dynamics control systems with an extendable bumper for collision mitigation. International Journal of Automotive and Mechanical Engineering. 2015;12:2893-913.

[16] Mottershead JE, Link M, Friswell MI. The sensitivity method in finite element model updating: a tutorial. Mechanical Systems and Signal Processing. 2011;25:2275-96.

[17] Palmonella M, Friswell MI, Mottershead JE, Lees AW. Finite element models of spot welds in structural dynamics: review and updating. Computers \& Structures. 2005;83:648-61. 
[18] Abdullah NAZ, Sani MSM, Rahman MM, Zaman I. Correlation of Numerical and Experimental Analysis for Dynamic Behavior of a Body-In-White (BIW) Structure. 2016.

[19] Zakaria KA, Jimit RH, Ramli SNR, Aziz AA, Bapokutty O, Ali MB. Study on fatigue life and fracture behaviour of fibreglass reinforced composites. Journal of Mechanical Engineering and Sciences. 2016;10:2300-10.

[20] Kranjc T, Slavič J, Boltežar M. The mass normalization of the displacement and strain mode shapes in a strain experimental modal analysis using the mass-change strategy. Journal of Sound and Vibration. 2013;332:6968-81.

[21] Bor-Tsuen W, Deng-Kai C. Modal analysis by free vibration response only for discrete and continuous systems. Journal of Sound and Vibration. 2011;330:391329.

[22] Goller B, Broggi M, Calvi A, Schueller G. A stochastic model updating technique for complex aerospace structures. Finite Elements in Analysis and Design. 2011;47:739-52.

[23] Nawayseh N. A mathematical model of the apparent mass of the human body under fore-and-aft whole-body vibration. International Journal of Automotive and Mechanical Engineering. 2016;13:3613-27.

[24] Jha SK, Sharma A. Optimal automobile muffler vibration and noise analysis. International Journal of Automotive and Mechanical Engineering. 2013;7:864-81.

[25] Esfandiari A. Structural model updating using incomplete transfer function of strain data. Journal of Sound and Vibration. 2014;333:3657-70.

[26] Hua-Peng C, Soe MT. Regularised finite element model updating using measured incomplete modal data. Journal of Sound and Vibration. 2014;333:5566-82.

[27] Husain NA, Khodaparast HH, Ouyang H. Parameter selections for stochastic uncertainty in dynamic models of simple and complicated structures. Proceedings of the 10th International Conference on Recent Advances in Structural Dynamics, University of Southampton, Southampton; 2010.

[28] Shun W, Yong X, You-Lin X, Hong-Ping Z. Substructure based approach to finite element model updating. Computers \& structures. 2011;89:772-82.

[29] Hatifi MM, Firdaus MH, Razlan AY. Modal Analysis of Dissimilar Plate Metal Joining with Different Thicknesses using MIG Welding. International Journal of Automotive and Mechanical Engineering. 2014;9:1723-33.

[30] Zainuddin H, Ali MB, Muhammad Said NB, Zakaria KA. Correlation between vertical wheel impact energy with lateral wheel impact energy: A finite element analysis approach. International Journal of Automotive and Mechanical Engineering. 2016;13:3574-83.

[31] Bohle K, Fritzen CP. Results obtained by minimising natural frequency and MAC-value errors of a plate model. Mechanical Systems and Signal Processing. 2003;17:55-64.

[32] Carne TG, Griffith DT, Casias ME. Support conditions for experimental modal analysis. Sound and Vibration. 2007;41:10-6.

[33] Rahman RA, Zubair M, Amin N. Finite element modeling, correlation and model updating of stiffened plate. Jurnal Mekanikal. 2003;16:91-106.

[34] Husain NA, Khodaparast HH, Ouyang H. Parameter selection and stochastic model updating using perturbation methods with parameter weighting matrix assignment. Mechanical Systems and Signal Processing. 2012;32:135-52.

[35] Wei-Ming L, Jia-Zhen H. New iterative method for model updating based on model reduction. Mechanical Systems and Signal Processing. 2011;25:180-92. 
[36] Noor MM, Devarajan R, Rejab MRM, Romlay FRM, Kadirgama K. Simulation of the corrosion point and repairing technique at the crane with finite element analysis. 2nd Regional Engineering Conference on Sustainable Engineering. 2008, p. 1-7.

[37] Ramasamy D, Goh CY, Rosli AB, Zainal ZA. Validation of road load characteristic of a sub-compact vehicle by engine operation. International Journal of Automotive and Mechanical Engineering 2014;9:1820-31. 